\title{
Visual Pathway
}

National Cancer Institute

\section{Source}

National Cancer Institute. Visual Pathway. NCI Thesaurus. Code C41445.

A set of neural connections within the central nervous system, beginning with the retina and terminating in the occipital cortex, that provides the ability to process visual images. 